\title{
Meiotic errors followed by two parallel postzygotic trisomy rescue events are a frequent cause of constitutional segmental mosaicism
}

\author{
Caroline Robberecht ${ }^{1}$, Thierry Voet ${ }^{1}$, Gülen E Utine ${ }^{1,2}$, Albert Schinzel $^{3}$, Nicole de Leeuw ${ }^{4}$, Jean-Pierre Fryns ${ }^{1}$ and \\ Joris Vermeesch ${ }^{1 *}$
}

\begin{abstract}
Structural copy number variation (CNV) is a frequent cause of human variation and disease. Evidence is mounting that somatic acquired CNVs are prevalent, with mosaicisms of large segmental CNVs in blood found in up to one percent of both the healthy and patient populations. It is generally accepted that such constitutional mosaicisms are derived from postzygotic somatic mutations. However, few studies have tested this assumption. Here we determined the origin of CNVs which coexist with a normal cell line in nine individuals. We show that in 2/9 the CNV originated during meiosis. The existence of two cell lines with 46 chromosomes thus resulted from two parallel trisomy rescue events during postzygotic mitoses.
\end{abstract}

Keywords: Segmental aneusomy, Duplication, Deletion, Somatic mosaicism, Constitutional, Mechanism, Prezygotic, Mitotic, Postzygotic, Meiotic

\section{Background}

For decades, knowledge about copy number variation (CNV) in the human genome was limited to microscopically visible changes. Advances in technology have led to the discovery of submicroscopic CNVs, ranging from kilobases to megabases in size and covering up to $13 \%$ of the human genome $[1,2]$. These CNVs can cause recurrent genomic disorders and sporadic disease, or they can represent benign changes found in the healthy population $[3,4]$. Recent studies have revealed that $\mathrm{CNVs}$ are not only polymorphic between unrelated individuals, but also form a frequent source of somatic variation $[5,6]$.

Chromosomal mosaicism is defined as the coexistence of two or more chromosomally different cell lines in an organism which developed from a single zygote. The majority of those mosaicisms are aneuploidies. Several studies investigating in vitro fertilized embryos at the preimplantation stage demonstrated a very high number of chromosomal mosaicisms in early human embryos

\footnotetext{
* Correspondence: Joris.Vermeesch@med.kuleuven.be

'Department of Human Genetics, Catholic University Leuven, Leuven, Belgium

Full list of author information is available at the end of the article
}

[7-9]. While many of these embryos will not reach the stage of implantation, some do continue to develop leading to fetal mosaicisms, confined placental mosaicism or mosaic infants. Postnatally, mosaicism is detected in $0.4-1 \%$ of patients referred for genetic diagnostic screening [10-12]. A recent study revealed that mosaic aberrations are present in about $0.8 \%$ of phenotypically normal adults [13]. In addition, mosaicism appears to be variable amongst different tissues: chromosomal aneuploidies were detected in approximately $10 \%$ of normal human brain cells [14].

Segmental aneuploidies make up a significant part of mosaic chromosome anomalies. Analysis of several large series of prenatal samples by karyotyping has shown that, of the $0.25-2 \%$ mosaic cases that are detected, up to a third comprise segmental imbalances $[15,16]$. In postnatal clinical diagnosis of patients with developmental anomalies this increases to about half of the mosaic cases $[10,17]$. The majority of mosaic segmental imbalances are marker chromosomes [16]. A smaller number of cases have been reported to consist of mosaic segmental deletions and/or duplications, ring chromosomes and translocations that have a 46 ,abnormal/46,normal karyotype. In recent years various case reports have
C Biomed Central

(c) 2012 Robberecht et al; licensee BioMed Central Ltd. This is an Open Access article distributed under the terms of the Creative Commons Attribution License (http://creativecommons.org/licenses/by/2.0), which permits unrestricted use, distribution, and reproduction in any medium, provided the original work is properly cited. 
been published [18-36]. The introduction of genome wide aneuploidy detection tools with a higher resolution such as array comparative genomic hybridisation (array CGH) or SNP arrays and the collection of large patient groups have also increased the detection rate of mosaic segmental abnormalities [10,12,17].

For mosaic aberrations, it is intuitively assumed that the rearrangement arose postzygotically. During embryogenesis, a mitotic rearrangement in an otherwise normal diploid embryo results in a second cell line carrying a chromosomal rearrangement. Nevertheless, evidence is mounting that such rearrangements can originate during meiosis. If so, a trisomic zygote carrying the abnormal chromosome has to be rescued twice, in parallel: once loosing the normal and once loosing the abnormal chromosome. Considering that the mitotic error rate is extremely high during early embryogenesis [7-9] and that most cases of mosaic aneuploidy detected in a large cohort of patients were of mitotic origin [11], we reasoned that the latter mechanism might be an important mechanism by which such mosaics arise. In this study we collected nine cases with mosaic structural imbalances to determine their origin and to ascertain whether a meiotic or postzygotic origin might be more prevalent.

\section{Results}

All nine samples contained two different cell lines, each with 46 chromosomes: one normal diploid cell line and a second cell line carrying a chromosomal rearrangement. In five cases the mosaicism was detected in blood lymphocytes, in three cases (case 4, 8 and 9) in amniocytes and in one case (case 6) in chorionic villi. In addition to the mosaicism present in the white blood cells, the mosaicism was confirmed in buccal cells in cases 7 and 9. Conventional karyotyping was carried out in five cases and detected the mosaicism in four out of five. Microarrays were performed on DNA from $8 / 9$ cases to identify or confirm the segmental aneuploidy, determine its size and rule out any additional chromosomal imbalances (Figures 1 and 2). The array intensity ratios indicated duplications in approximately 66, 55, 53, 72 and $15 \%$ of the cells in patients $1,2,3,4$ and 5 respectively.
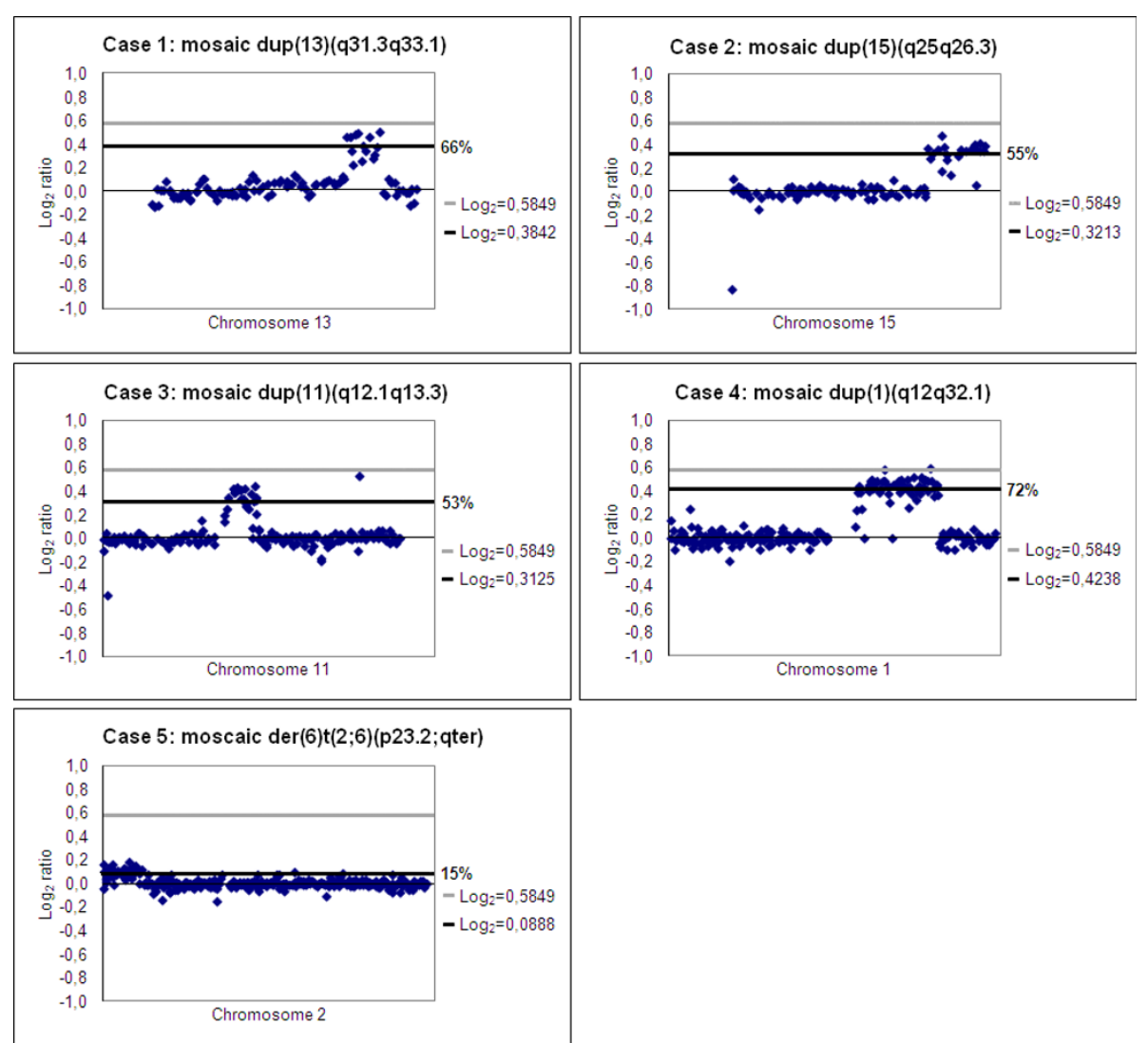

Figure 1 Microarray profiles of the affected chromosome in cases 1, 2, 3, $\mathbf{4}$ and $\mathbf{5}$. The dots on the X-axis represent the BAC clones ordered from the short-arm telomere to the long-arm telomere. The $Y$-axis shows $\log _{2}$ transformed intensity ratios of the combined dye-swap BAC array experiments (case Cy5/control Cy3). The grey bar indicates the theoretical $\log _{2}$ ratio of a non-mosaic duplication, while the thick black bars indicate the individual mosaicism level per case. 


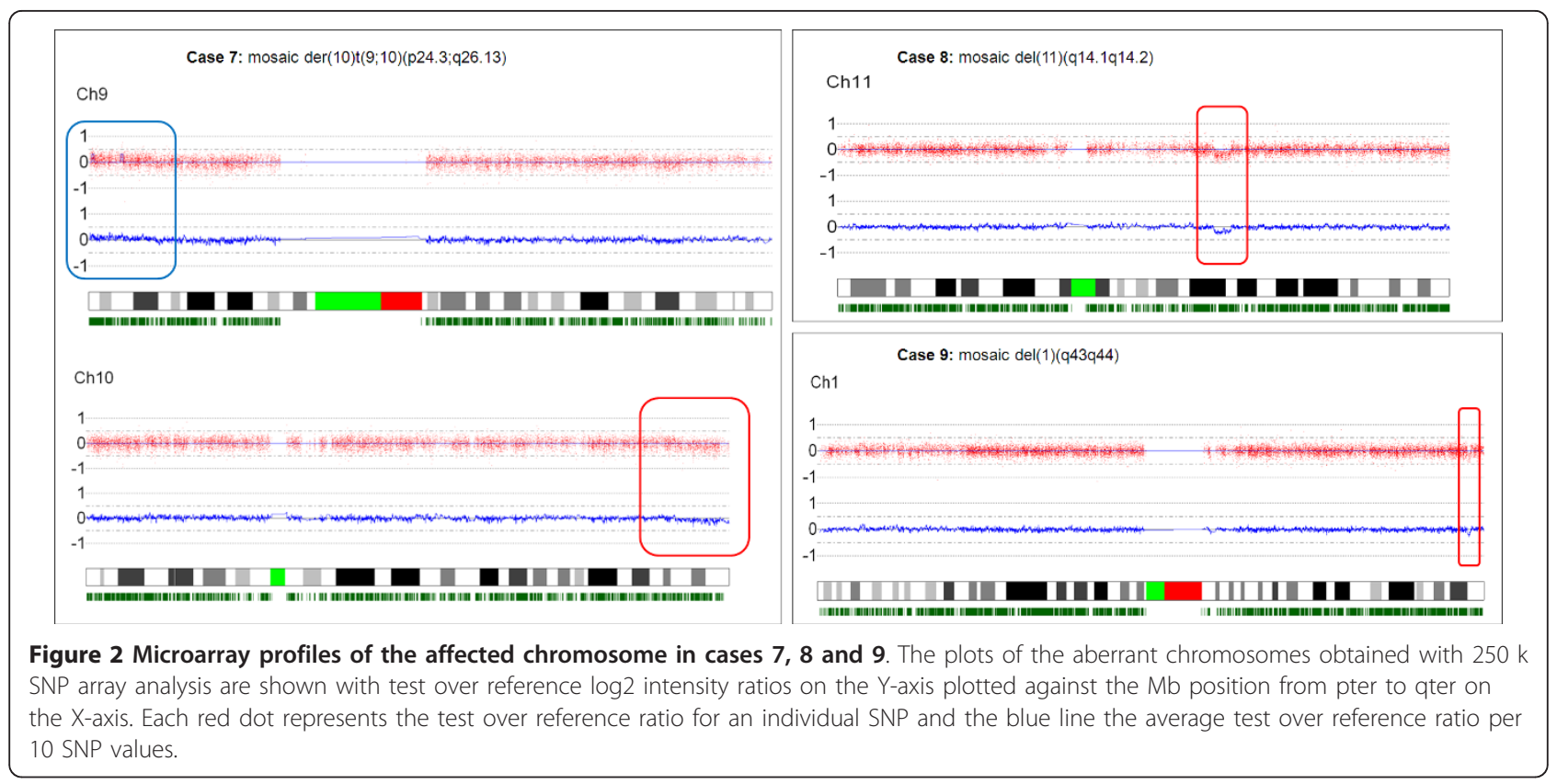

The array intensity ratios indicated the presence of segmental deletions in approximately 20 and $30 \%$ of the cells in samples 8 and 9. In two samples, 6 and 7, both deletions and duplications were identified by karyotyping (case 6) or array CGH (case 7) in respectively 50 and $20 \%$ of the cells. Conventional karyotyping showed those imbalances to be unbalanced translocations. FISH confirmed the mosaic segmental imbalances in six samples. FISH also determined that the duplication in cases 1 and 4 was not translocated to another chromosome and that cases 5 and 7 carry unbalanced translocations. The karyotypes are presented in Table 1 . The degree of mosaicism was estimated based on the intensity ratios of the targets located within the segmental aneuploidy or on data from FISH analysis. The segment sizes and estimated relative presence of the segmental aneuploidy range between 1 and $124 \mathrm{Mb}$ and an overview is shown in Table 1. Chromosome analysis of the parents, including FISH for submicroscopic aberrations, was normal for all.

To determine whether the initial rearrangement occurred during meiosis or during postzygotic mitosis, polymorphic marker analysis or SNP array analysis was performed. For patients 1 to 6 , carrying segmental duplications, markers were selected within and flanking the duplicated region. If the duplication arose during meiosis, three alleles might be observed. If only two alleles are detected, there are two possible explanations: either the duplication arose postzygotically or the duplication arose during meiosis and the segmental

Table 1 Combined karyotypes after conventional and molecular cytogenetic analyses

\begin{tabular}{|c|c|c|c|}
\hline case & Karyotype (ISCN 2009; Mb positions mapped in hg19) & $\begin{array}{l}\text { \% } \\
\text { mos }\end{array}$ & del/dup size \\
\hline 1 & 46,XX,dup(13)(q31.3q33.1)dn/46,XX.arr 13q31.3q33.1 (RP11-319 L6-RP11-564 N10)x2 3 & $66 \%$ & $11.11 \mathrm{Mb}$ \\
\hline 2 & 46,XX,dup(15)(q25q26.3)dn/46,XX.arr 15q25.2q26.3 (RP11-365 F16-CTB-154P1)2 3 & $55 \%$ & $18.25 \mathrm{Mb}$ \\
\hline 3 & 46,XY,dup(11)(q12.1q13.3)dn/46,XY.arr 11q12.1q13.3 (RP11-131 J4-RP11-804 L21)2 3 & $53 \%$ & $14.55 \mathrm{Mb}$ \\
\hline 4 & 46,XY,dup(1)(q12q32.1)dn/46,XY.arr 1q12q32.1 (RP11-417 J8-RP11-383 G10)2 3 & $72 \%$ & $62.72 \mathrm{Mb}$ \\
\hline 5 & 46,XX,der(6)t(2;6)(p23.2;qter)dn/46,XX.arr 2p25.3p23.2 (GS1-68 F18-RP11-328 L16)2 3 & $15 \%$ & $29.36 \mathrm{Mb}$ \\
\hline 6 & $46, X Y, \operatorname{der}(20) t(1 ; 20)(10 q ; 10 p) d n / 46, X Y *$ & $50 \%$ & $\begin{array}{l}25.56 \mathrm{Mb} / 124.2 \\
\mathrm{Mb}\end{array}$ \\
\hline 7 & 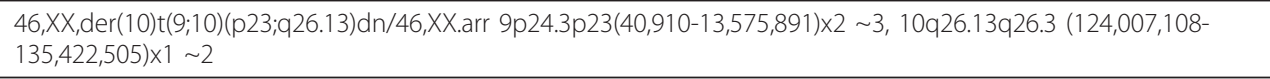 & $20 \%$ & $\begin{array}{l}13.53 \mathrm{Mb} / 11.31 \\
\mathrm{Mb}\end{array}$ \\
\hline 8 & 46,XX.ish del(11)(q14.1q14.2)(RP11-118 L16-,RP11-157B22-)dn[21/50].arr 11q14.1q14.2(83,122,844-86,794,856)x1 2 & $20 \%$ & $3.7 \mathrm{Mb}$ \\
\hline 9 & 46,XX.ish del(1)(q43g44)(RP11-113011-,RP11-370 K11-)dn[25/50].arr 1q43g44(242,916,876-243,920,382)x1 2 & $30 \%$ & $\sim 1 \mathrm{Mb}$ \\
\hline
\end{tabular}


duplication is one of both sister chromatids present during meiosis I or II. Results of the short tandem repeat (STR) analyses are shown in Figures 3, 4 and 5 and a summary is presented in Table 2 .

For two samples, three different alleles were detected within the duplicated region indicating a meiotic origin. Polymorphic marker analysis of sample 1 revealed the presence of three different alleles for marker D13S128 (Figure 3A). Two of the alleles were inherited from the father demonstrating the paternal origin of the segmental aneusomy. At marker D13S129, still within the duplication, two alleles with a 2:1 intensity ratio were detected, including only one of the two paternal alleles (Figure 3B). The remaining markers within the duplication were not informative. In case 6 , carrier of an unbalanced translocation, two markers (D1S1653 and D1S1171) spread throughout the duplicated 1q region showed three different alleles (Figure 4). The other markers on 1q had either one or two alleles. Marker D20S117 in the deleted 20p region confirmed the deletion, with a 1:2 reduced peak intensity for one of both alleles.

For the other cases, only two different alleles were identified within the duplication region. Genotyping of cases 2 to 5 within the region of duplication showed in each case only two alleles. One of both alleles clearly had a higher intensity with about a 2:1 ratio (Figure 5). For sample 5, in which array $\mathrm{CGH}$ revealed that the rearrangement is only present in 10 to $20 \%\left(\log _{2}\right.$ value of 0.0888) of all cells, these peak intensity differences were still present, but to a lesser extent.

For patients 7 to 9 with mosaic segmental deletions, single nucleotide polymorphisms were analyzed by 250 K Affymetrix SNP arrays. To determine the origin of the mosaic unbalanced translocation in case 7, genotyped by Affymetrix SNP arrays, the following strategy was followed: the A and B allele ratios of individual SNPs within the segmental mosaic duplication and deletion were determined for those SNPs that were homozygous but with a different allele in both parents. Analysis of the $\mathrm{A}$ and $\mathrm{B}$ allele ratios transmitted from parental homozygous AA and BB SNPs showed 77 SNPs to fulfill this criteria in the duplication and 51 SNPs in the deletion and demonstrated a paternal origin for both the deleted and the duplicated segments of the unbalanced translocation. Subsequently, the A and B allele ratios of SNPs in the duplicated region that were paternal heterozygous but maternal homozygous were interrogated. Analysis of the SNPs did not show transmission of both paternal alleles. Only a single duplicated allele from the father was detected (Figure 6A).

To determine the origin of the deletion in cases 8 and 9, again for the SNPs that were homozygous but with a different allele in both parents in the deletion, the A and $\mathrm{B}$ allele ratios were determined. The analysis showed that the signal of the paternal allele was reduced in case 8 and that a maternal allele was removed in case 9. To search for evidence of a potential meiotic event,

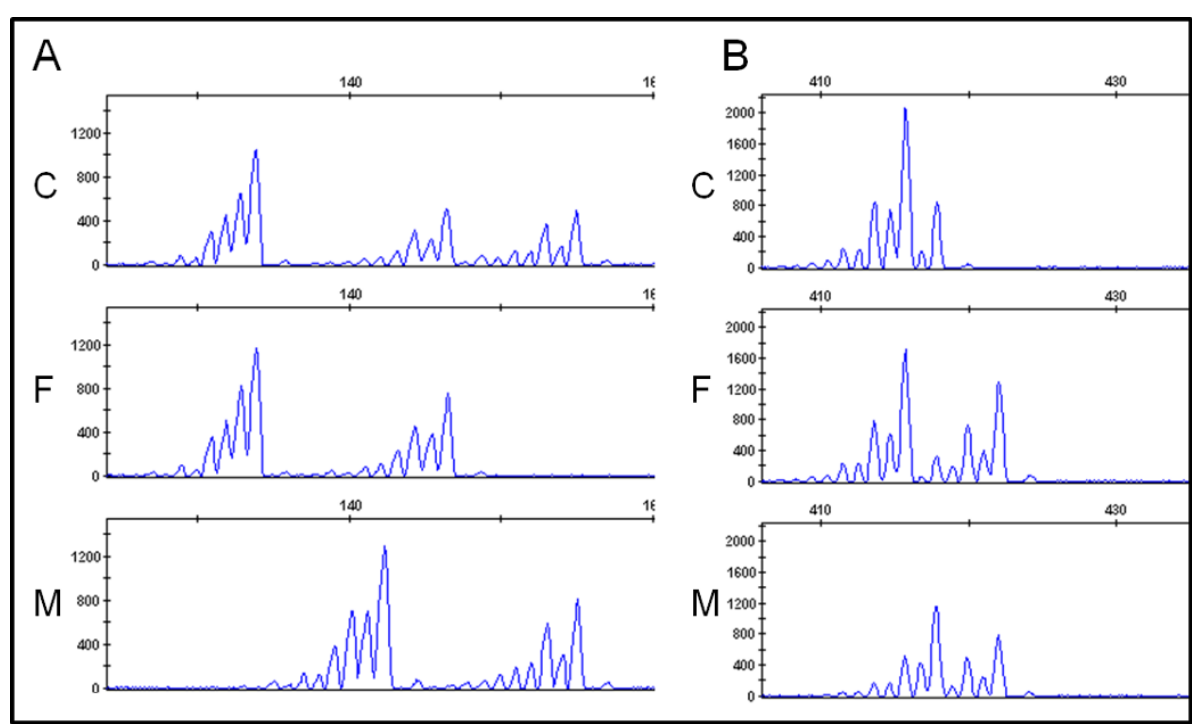

Figure 3 Short tandem repeat analysis on DNA of the patient and parents. A) Case 1 has three different alleles for marker D13S128 corresponding to two different paternal alleles and one maternal allele. B) At marker D13S129 case 1 has two identical paternal alleles and one maternal allele. This indicates the paternal origin of the duplication in chromosome 13 and suggests a cross-over occurred between the paternal chromosomes 13 followed by a meiosis II non-disjunction and an unequal sisterchromatid exchange. C: case, F: father, M: mother. 


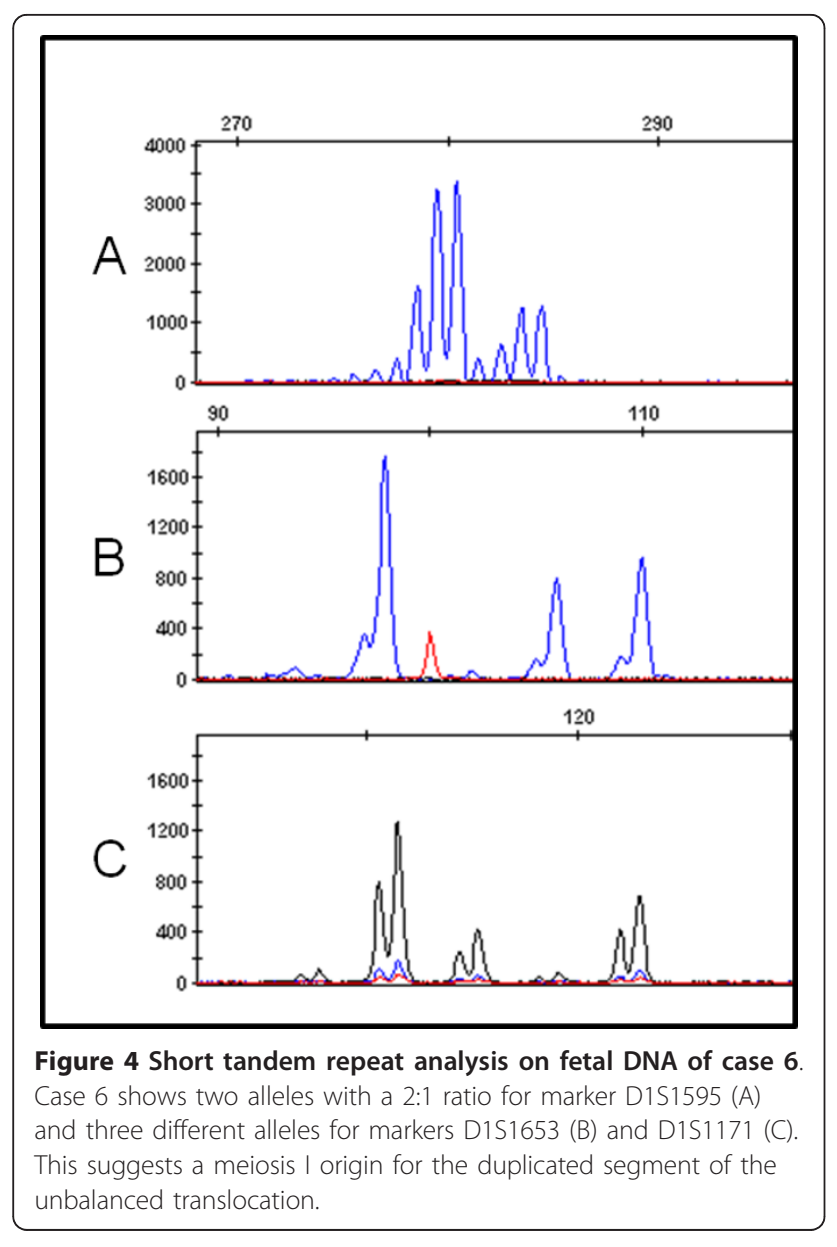

the rest of the chromosome was screened for the presence of two paternal (case 8) or two maternal alleles (case 9). Hereto, the B-allele frequencies of SNPs on the affected chromosome, but outside the somatic CNV region, were evaluated for additional haplotypes. If the deletion resulted from a meiotic event, altered B-allele frequencies would be observed, with additional values between 0 and 0.5 as well as between 0.5 and 1 . No such haplotypes were detected in the regions surrounding the deletion (Figure 6B).

The combination of a normal and an aberrant cell line in these cases could, aside from mosaicism, also result from chimerism: the fusion of two cell lineages from separate fertilization events. In samples 1 to 6 , the presence of chimerism was evaluated by testing four STR markers spread over different chromosomes not involved in the aberrant region. in case of a mosaic all autosomal genotypes outside the duplicated region are expected to only contain two alleles ( 1 maternal \& 1 paternal). For chimeras, some loci would have three or four alleles, or a skewed dosage of two alleles [37]. None of the samples showed more than two alleles on any of the markers, confirming the mosaic status of the aberration (data not shown). In cases 7 to 9 , the two different genotypes present in case of chimerism would be seen as aberrant B-allele frequencies in all autosomes, with an altered ratio between the two haplotypes. No alterations in the B-allele frequency were seen in the unaffected chromosomes, thereby ruling out the possibility of chimerism.

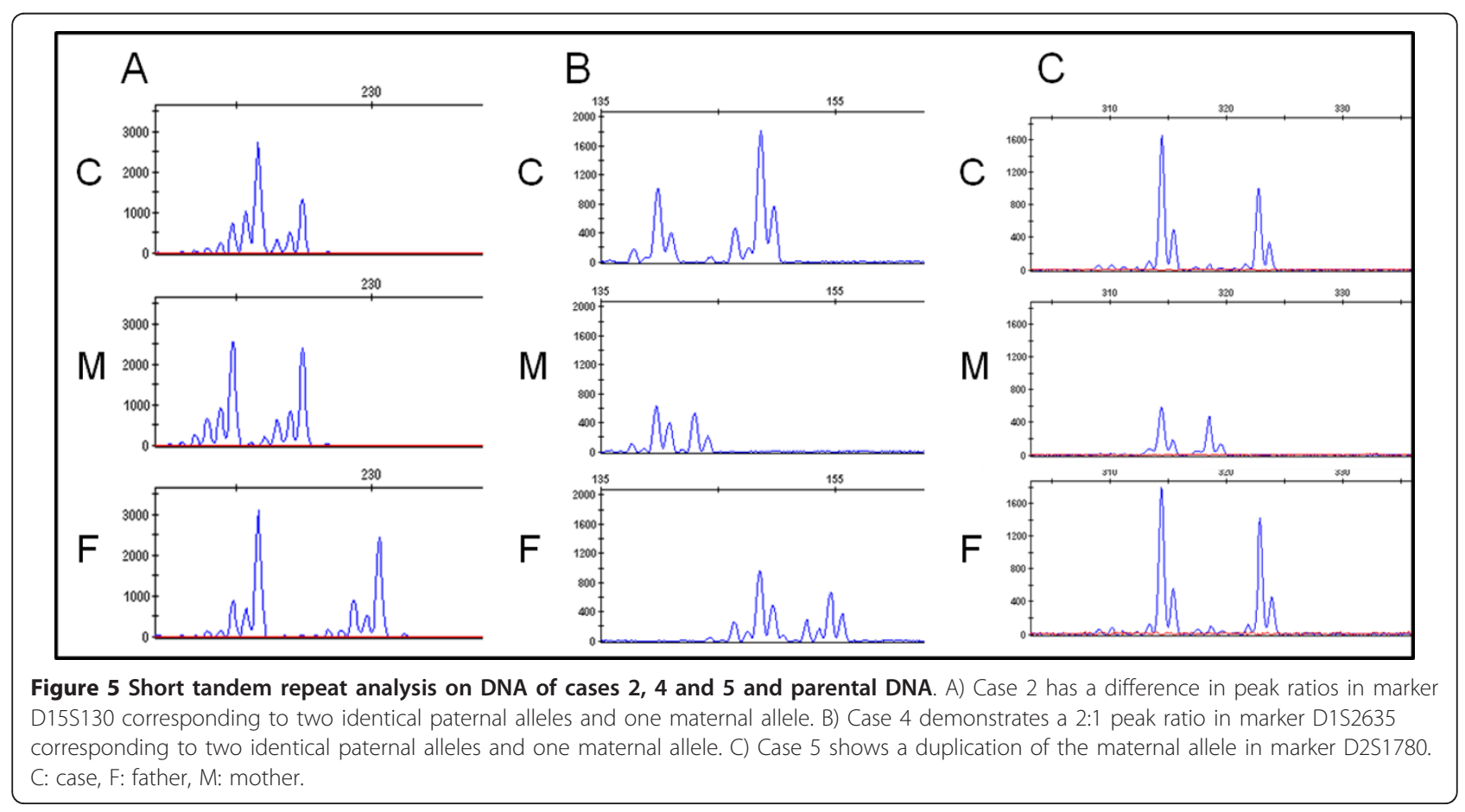


Table 2 Results of the STR marker analysis

\begin{tabular}{|c|c|c|c|}
\hline case 1 & marker & location & $\mathrm{F} / \mathrm{C} / \mathrm{M}$ \\
\hline & D13S232 & $13 q 12.12$ & $\mathrm{ac} / \mathrm{ac} / \mathrm{ab}$ \\
\hline & D13S129 & $13 q 31.3$ & $\mathrm{ac} / \mathbf{a a b} / \mathrm{bc}$ \\
\hline & D13S128 & $13 q 32.2$ & $\mathrm{ac} / \mathbf{a c d} / \mathrm{bd}$ \\
\hline & D13S770 & $13 q 32.3$ & $a b / a a b / a b$ \\
\hline & D13S779 & $13 q 32.3$ & ab/aab/ac \\
\hline & D13S1315 & $13 q 34$ & $\mathrm{ac} / \mathrm{bc} / \mathrm{ab}$ \\
\hline & D13S285 & $13 q 34$ & $\mathrm{~b} / \mathrm{bc} / \mathrm{ac}$ \\
\hline \multirow[t]{7}{*}{ case 2} & marker & location & $F / C / M$ \\
\hline & D15S165 & $15 q 13.2-q 13.3$ & $a b / a b / a c$ \\
\hline & D15S222 & $15 q 21.1$ & ab/ab/ab \\
\hline & D15S116 & $15 q 26.1$ & $\mathrm{bc} / \mathrm{bbc} / \mathrm{ac}$ \\
\hline & D15S127 & $15 q 26.1$ & $\mathrm{~cd} / \overline{\mathbf{b d d}} / \mathrm{ab}$ \\
\hline & D15S158 & $15 q 26.1$ & $\mathrm{ac} / \mathbf{b c c} / \mathrm{ab}$ \\
\hline & D15S130 & $15 q 26.2$ & $\mathrm{bd} / \overline{\mathbf{b b} \boldsymbol{c}} / \mathrm{ac}$ \\
\hline \multirow[t]{9}{*}{ case 3} & marker & Location & $\mathrm{F} / \mathrm{C} / \mathrm{M}$ \\
\hline & D11S1357 & $11 q 12.1$ & $\mathrm{~b} / \mathrm{b} / \mathrm{ab}$ \\
\hline & D11S480 & $11 q 12.3$ & $\mathrm{bd} / \underline{\mathbf{b b c}} / \mathrm{ac}$ \\
\hline & D11S913 & $11 q 13.1-q 13.2$ & $? / \mathrm{aac} / \mathrm{bc}$ \\
\hline & D11S4095 & $11 q 13.3$ & $\mathrm{bc} / \mathbf{a b b} / \mathrm{ad}$ \\
\hline & D11S1314 & $11 q 13.4$ & $? / \mathrm{bc} / \mathrm{ab}$ \\
\hline & D11S916 & $11 q 13.4$ & $? / a / a$ \\
\hline & D11S1339 & $11 q 22.1-q 22.2$ & ?/ab/ac \\
\hline & D11S4111 & $11 \mathrm{q} 23.3$ & ?/bc/ab \\
\hline \multirow[t]{8}{*}{ case 4} & marker & location & $\mathrm{F} / \mathrm{C} / \mathrm{M}$ \\
\hline & D1S1595 & $1 q 22$ & $\mathrm{ac} / \mathrm{c} / \mathrm{bc}$ \\
\hline & D1S1653 & $1 q 23.1$ & ?/b/ab \\
\hline & D1S2635 & $1 q 23.2$ & $\mathrm{~cd} / \mathrm{acc} / \mathrm{ab}$ \\
\hline & D1S2705 & $1 \mathrm{q} 23.3$ & $\mathrm{ac} / \overline{\mathbf{a a b}} / \mathrm{b}$ \\
\hline & D1S212 & $1 q 25.2$ & $\mathrm{ac} / \overline{\mathbf{b c c}} / \mathrm{bd}$ \\
\hline & D1S1171 & $1 q 32.1$ & $? / a / a b$ \\
\hline & D1S2631 & $1 \mathrm{q} 42.13$ & $a / a b / a b$ \\
\hline \multirow[t]{5}{*}{ case 5} & marker & location & $\mathrm{F} / \mathrm{C} / \mathrm{M}$ \\
\hline & D2S2268 & $2 p 25.3$ & $\mathrm{~b} / \mathrm{b} / \mathrm{ab}$ \\
\hline & $\mathrm{D} 2 \mathrm{~S} 2245$ & $2 \mathrm{p} 25.3$ & $\mathrm{ac} / \mathbf{b b c} / \mathrm{bc}$ \\
\hline & D2S319 & $2 p 25.3$ & $\mathrm{ab} / \mathbf{b c c} / \mathrm{bc}$ \\
\hline & D2S1780 & $2 p 25.3$ & $\mathrm{ac} / \mathrm{aac} / \mathrm{ab}$ \\
\hline \multirow[t]{7}{*}{ case 6} & marker & location & \\
\hline & D1S1595 & $1 q 22$ & $a a b$ \\
\hline & D1S1653 & $1 q 23.1$ & $\underline{a b c}$ \\
\hline & D1S2635 & $1 q 23.2$ & $a b$ \\
\hline & D1S2705 & $1 q 23.3$ & a \\
\hline & D1S212 & $1 q 25.2$ & $a b$ \\
\hline & D1S1171 & $1 q 32.1$ & $a b c$ \\
\hline \multirow[t]{2}{*}{ case 6} & marker & location & \\
\hline & D20S117 & 20p13 & $a b$ \\
\hline
\end{tabular}

Results of the STR marker analysis. Highlighted markers lie within the duplicated or deleted regions. Informative marker results are underlined and highlighted. F: father, C: case, M: mother.

\section{Discussion}

Somatic chromosomal mosaicisms are thought to arise from postzygotic somatic mutations. Here, we show that in two out of nine cases $(>15 \%)$ the rearrangements occurred preconception. Cases 1 and 6 showed markers with three different alleles in the duplicated region. The most parsimonious explanation is that both aberrations originated from a meiotic segregation error resulting in a trisomic conception, followed by two parallel trisomy rescue events during the successive mitotic divisions (Figure 7). In the other seven cases (pt 2-5 \& pt 7-9), the duplication was derived from the chromosome with the same parental allele as the transmitted chromosome in the normal cell line or the deletion was on the chromosome with the same parental allele as the normal chromosome in the normal cell line. In these cases the copy variation likely occurred during postzygotic cell divisions. Nevertheless, those rearrangements could also have occurred during meiosis II. Hence, the percentage of mosaic segmental imbalances generated during meiosis by two separate postzygotic trisomy rescue events could be higher than $15 \%$. The occurrence of multiple postzygotic trisomy rescue events may appear to be unexpected. However, a high frequency of mosaic trisomies and monosomies is reported to occur during cleavage stage in in vitro fertilized embryos [7-9]. The observation that two independent trisomy rescue events can underlie those mosaicisms is further testimony of this high mutational burden during early embryogenesis. Postzygotic trisomy rescue events are also frequently observed in patients with imprinting diseases, including Prader-Willi syndrome and Silver-Russell syndrome. Such patients may be fully disomic with complete uniparental disomy (UPD) or be mosaic with a trisomic and a disomic (UPD) cell line [11,38-40].

While the origin of mosaic segmental CNVs has only rarely been investigated, two case reports support our finding that pre-zygotic rearrangements followed by multiple postzygotic trisomy rescue events can underlie segmental mosaicisms. Blouin et al. detected a mosaic de novo direct tandem duplication of $21 \mathrm{q} 11.2 \mathrm{q} 22.2$ that resulted from a meiosis I crossover followed by an unequal sister chromatid exchange and two trisomy rescue events, similar to our case 1 . The mosaic de novo unbalanced translocation with partial trisomy 16p and maternal UPD 16 reported by Schinzel et al. likely originated from a maternal trisomy 16 (MI), a subsequent postzygotic translocation of the paternal $16 \mathrm{p}$ segment and finally loss of the paternal chromosomes 16 in the translocated and normal cell lines [18,32]. Even after combining our results with previous mosaic segmental cases the total study population remains small, but 


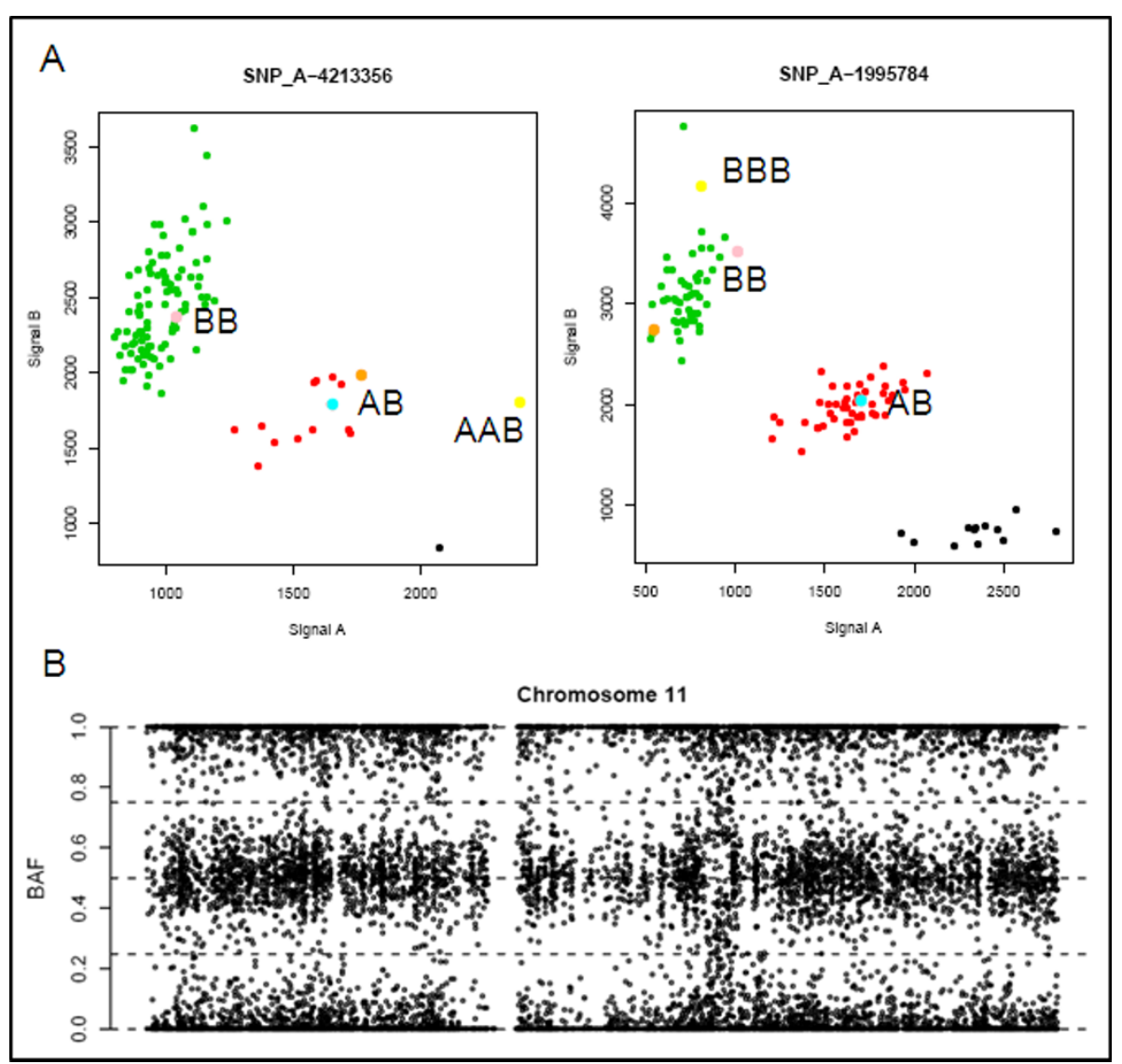

Figure 6 SNP array analysis of cases 7 and 8. A) SNP cluster plots of individual SNPs. Green, red and black dots represent controls with a BB, $A B$ and $A A$ genotype respectively. The pink and blue dots represent the genotypes of the mother and father. The yellow dots indicate the genotype of case 7 in cells with the duplication, while the orange dots give the genotype of the normal cells of the fetus. The SNPs shown are located within the paternal duplication. The plots indicate that paternal heterozygous SNPs in the duplicated region do not show transmission of both paternal alleles, but instead revealed a duplication of one of the paternal alleles. This suggests the duplication originated during postzygotic mitosis or meiosis II. B) The B allele frequency graph of chromosome 11 shows abnormal heterozygous values without complete loss of heterozygosity in the deleted segment in case 8 . No additional haplotypes are found in the regions surrounding the deletion. This rules out the possibility of a trisomy rescue and indicates the deletion originated during postzygotic mitosis or meiosis $\mathrm{II}$.

future studies may be able to provide additional evidence for the high frequency of multiple independent trisomy rescue events.

\section{Conclusions}

In conclusion, we demonstrated that in $2 / 9$ cases, the detected mosaic segmental aberrations resulted from meiotic errors followed by multiple parallel trisomy rescue events and not from postzygotic mitotic changes. In addition, we show that the use of sensitive array technology is especially suited for the detection of mosaicism, which is clinically relevant to a patient's diagnosis.

\section{Methods}

\section{Patient selection}

Five cases were referred for cytogenetic/molecular investigations after clinical evaluation for dysmorphic features, whereas cases 4, 6, 8 and 9 were ascertained during prenatal diagnosis (CVS and/or amniocentesis).

\section{Cytogenetic Analysis}

Cytogenetic analyses were performed on GTG-banded metaphase chromosomes from PHA-stimulated peripheral blood lymphocytes or from CVS cells or amniocytes after standard culture and chromosome preparation protocols. Twenty metaphases with a resolution of 550 bands per haploid genome were karyotyped (ISCN 2009).

BAC microarray analysis was performed as described elsewhere [41]. Briefly, CodeLink Bioarray System slides (Amersham Biosciences, Chalfont St.Giles, UK) were used for array construction using a $1 \mathrm{Mb}$ clone set of 3683 $\mathrm{BAC}$ and PAC clones. Genomic DNA from the index patient and two other patients was labelled in $\mathrm{Cy} 3$ and Cy5, respectively (Amersham Biosciences, Chalfont St. 

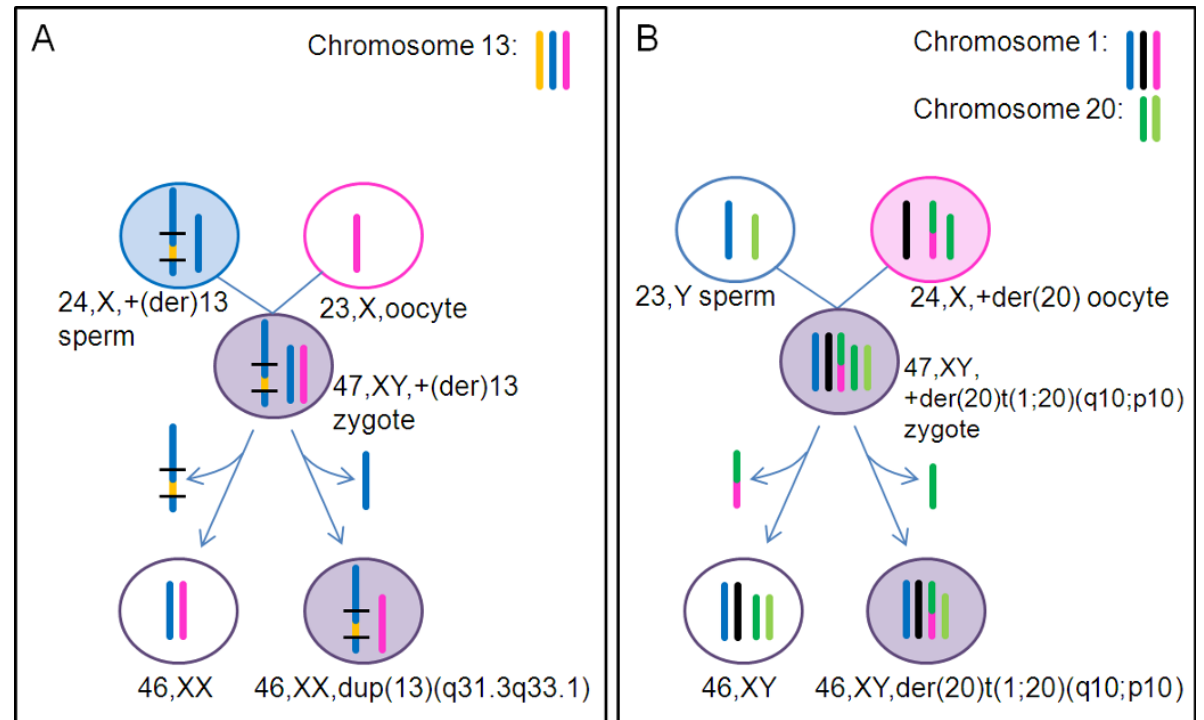

Figure 7 Schematic representation of the events leading to the mosaicism in cases 1 and 6 . A) In case 1, there was likely a recombination between the two paternal homologous chromosomes 13, followed by a duplication of part of the recombined chromosome. A subsequent nondisjunction resulted in a trisomic zygote, that lead to a normal and an abnormal cell line through two trisomy rescue events. B) The mosaicism in case 6 presumably originated from a translocation between chromosome 1 and chromosome 20 during meiosis I, with segregation of a normal and a derivative chromosome 20 to the zygote. This results in a zygote which is trisomic for chromosome 20p and 1q and could lead to the mosaicism seen in this case by trisomy rescue of the derivative chromosome (normal cells) and trisomy rescue of a normal chromosome 20 (abnormal cells).

Giles, UK) with random prime labelling (Bioprime array $\mathrm{CGH}$, Invitrogen, Sunnydale, CA) and hybridized in a 3way experiment. Hybridization and post-hybridization washing steps were performed as previously described [41]. Slides were scanned at $532 \mathrm{~nm}(\mathrm{Cy} 3)$ and $635 \mathrm{~nm}$ (Cy5) using a GenePix 4000B microarray scanner (Axon Instruments, Union City, CA) with the software GenePixPro 6.0. Data analysis was performed with Excel (Microsoft Inc.; Diegem, Belgium) as described [41]. The percentage of mosaicism was calculated by dividing the mean $\log 2$ ratio of the $\mathrm{BAC}$ clones in the duplicated region by the $\log 2$ of a non-mosaic aberration (0.5849).

SNP array analysis was performed on Affymetrix GeneChip ${ }^{\circledR}$ Human Mapping $250 \mathrm{~K}$ NspI arrays (Affymetrix, Inc., Santa Clara CA, USA) containing 25-mer oligonucleotides representing a total of 262264 SNPs. DNA digestion, labeling and hybridization were performed according to the manufacturer's protocol. After hybridization, arrays were washed and stained on the Affymetrix GeneChip fluidics station 450 and scanned using the Affymetrix GeneChip ${ }^{\circledR}$ Scanner 30007 G. Data analysis was performed using Copy Number Analyzer for GeneChip version 2.0 (CNAG 2.0) [42] and Genotyping Console ${ }^{\mathrm{TM}}$ Software (Affymetrix, Inc.).

\section{Fluorescent in situ hybridization}

To confirm aberrations found by microarray, FISH was performed with BAC probes as described [43], using an optical fluorescence microscope (Olympus U-SPT, BX51, Japan) with selective filters equipped with CytoVision ${ }^{\circledR}$ software (Applied Imaging, Genetix, Gateshead, UK).

\section{SNP cluster determination}

For determining the parental origin of the DNA copy number aberrations by a SNP-cluster strategy, normalized SNP A and B allele intensities as well as SNP genotype calls were computed using Affymetrix power tools (APT-1.10.1) in combination with the Birdseed command [44]. Besides the described trio datasets, in-house produced Affymetrix $250 \mathrm{~K}$ SNP NspI data from 102 additional DNA samples were co-processed for accurate SNP cluster and genotype determination. Subsequently, the probe intensities and genotype calls for SNPs within the regions of interest were retrieved for all DNA samples and interpreted by custom R-code [45] in which patient and parental SNP-probe intensities are visualised in the Birdseed SNP clusters from the 102 individuals.

\section{B-allele frequency plots}

To generate the B-allele frequency (BAF) plots, copy number analysis of the SNP array data was performed using the Affymetrix power tools BRLMM, a modified version of RLMM [46] and the pennCNV [47] algorithm. These data were subsequently further interpreted and visualized in BAF and $\log \mathrm{R}$ ratio plots by the genoCN algorithm [48]. 


\section{Polymorphic microsatellite marker analysis}

Polymorphic microsatellite markers made up of dinucleotide (CA)n repeats (short tandem repeats or STRs) were selected from the Ensembl [49] and UCSC [50] genome browser databases and the oligonucleotides were purchased from Eurogentec S.A. (Seraing, Belgium) and Pharmacia Biotech (Uppsala, Sweden). Genomic DNA was extracted from peripheral blood leukocytes, amniocytes or CVS cells of the patients and their parents according to standard procedures and CA repeats spaced along the involved chromosomes were amplified by polymerase chain reaction (PCR). DNA extracted from skin fibroblasts was also included in the analysis in case the mosaicism was encountered in fibroblasts.

After PCR amplification of the STRs, fragments were analyzed by gel electrophoresis. Automated fragment sizing was performed on the ABI Prism 3100 Genetic Analyzer (Applied Biosystems, Nieuwerkerk a/d Ijssel, the Netherlands), using software GeneScan or Genemapper v4.0 (Applied Biosystems, Nieuwerkerk a/d Ijssel, The Netherlands).

\section{Acknowledgements}

This work has been made possible by an IWT (SBO 60848) and FWO grant G.0320.07.

\section{Author details}

'Department of Human Genetics, Catholic University Leuven, Leuven, Belgium. ${ }^{2}$ Department of Pediatrics, Division of Genetics, Hacettepe University, Ankara, Turkey. ${ }^{3}$ Institute of Medical Genetics, University of Zürich, Zürich, Switzerland. ${ }^{4}$ Department of Human Genetics, Radboud University Nijmegen Medical Centre, Nijmegen, the Netherlands.

\section{Authors' contributions}

CR carried out the molecular genetic studies, analyzed the results and drafted the manuscript. TV performed the SNP cluster determination and helped to draft the manuscript. SA participated in the design of the study and helped to draft the manuscript. GU participated in the molecular genetic studies and the results analysis. DLN carried out the SNP arrays and analyzed the data. JV conceived of the study, participated in its design and coordination and helped to draft the manuscript. All authors read and approved the final manuscript.

\section{Competing interests}

The authors declare that they have no competing interests.

Received: 17 February 2012 Accepted: 10 April 2012

Published: 10 April 2012

\section{References}

1. Conrad DF, Pinto D, Redon R, Feuk L, Gokcumen O, Zhang YJ, Aerts t, Andrews TD, Barnes C, Campbell P, Fitzgerald T, Hu M, Ihm CH, Kristiansson K, MacArthur DG, MacDonald JR, Onyiah I, Pang AWC, Robson S, Stirrups K, Valsesia A, Walter K, Wei J, Tyler-Smith C, Carter NP Lee C, Scherer SW, Hurles ME: Origins and functional impact of copy number variation in the human genome. Nature 2010, 464:704-712.

2. Sebat J, Lakshmi B, Troge J, Alexander J, Young J, Lundin P, Maner S, Massa H, Walker M, Chi MY, Navin N, Lucito R, Healy J, Hicks J, Ye K, Reiner A, Gilliam TC, Trask B, Patterson N, Zetterberg A, Wigler M: Largescale copy number polymorphism in the human genome. Science 2004, 305:525-528

3. Lupski JR: Genomic rearrangements and sporadic disease. Nat Genet 2007, 39:S43-S47.
4. Shaw CJ, Lupski JR: Implications of human genome architecture for rearrangement-based disorders: the genomic basis of disease. Hum Mol Genet 2004, 13:R57-R64.

5. Bruder CEG, Piotrowski A, Gijsbers AACJ, Andersson R, Erickson S, de Stahl TD, Menzel U, Sandgren J, von Tell D, Poplawski A, Crowley M, Crasto C, Partridge EC, Tiwari H, Allison DB, Kornorowski J, van Ommen GJB, Boomsma DI, Pedersen NL, den Dunnen JT, Wirdefeldt K, Dumanski JP: Phenotypically concordant and discordant monozygotic twins display different DNA copy-number-variation profiles. Am J Hum Genet 2008, 82:763-771.

6. Piotrowski A, Bruder CEG, Andersson R, de Stahl TD, Menzel U, Sandgren J Poplawski A, von Tell D, Crasto C, Bogdan A, Bartoszewski R, Bebok Z, Krzyzanowski M, Jankowski Z, Partridge EC, Komorowski J, Dumanski JP: Somatic mosaicism for copy number variation in differentiated human tissues. Hum Mutat 2008, 29:1118-1124.

7. Vanneste $E$, Voet $T$, Le Caignec C, Ampe M, Konings P, Melotte C, Debrock S, Amyere M, Vikkula M, Schuit F, Fryns JP, Verbeke G, D'Hooghe T, Moreau Y, Vermeesch JR: Chromosome instability is common in human cleavage-stage embryos. Nat Med 2009, 15:577-583.

8. Voullaire L, Slater $H$, Williamson R, Wilton L: Chromosome analysis of blastomeres from human embryos by using comparative genomic hybridization. Hum Genet 2000, 106:210-217.

9. Wells D, Delhanty JDA: Comprehensive chromosomal analysis of human preimplantation embryos using whole genome amplification and single cell comparative genomic hybridization. Mol Hum Reprod 2000, 6:1055-1062

10. Ballif BC, Rorem EA, Sundin K, Lincicum M, Gaskin S, Coppinger J, Kashork CD, Shaffer LG, Bejjani BA: Detection of low-level mosaicism by array CGH in routine diagnostic specimens. Am J Med Genet A 2006, 140:2757-2767.

11. Conlin LK, Thiel BD, Bonnemann CG, Medne L, Ernst LM, Zackai EH, Deardorff MA, Krantz ID, Hakonarson H, Spinner NB: Mechanisms of mosaicism, chimerism and uniparental disomy identified by single nucleotide polymorphism array analysis. Hum Mol Genet 2010, 19:1263-1275.

12. Cheung SW, Shaw CA, Scott DA, Patel A, Sahoo T, Bacino CA, Pursley A, Li J, Erickson R, Gropman AL, Miller DT, Seashore MR, Summers AM, Stankiewicz P, Chinault AC, Lupski JR, Beaudet AL, Sutton VR: Microarraybased $\mathrm{CGH}$ detects chromosomal mosaicism not revealed by conventional cytogenetics. Am J Med Genet A 2007, 143A:1679-1686.

13. Rodriguez-Santiago B, Malats N, Rothman N, Armengol L, Garcia-Closas M, Kogevinas M, Villa O, Hutchinson A, Earl J, Marenne G, Jacobs K, Rico D, Tardon A, Carrato A, Thomas G, Valencia A, Silverman D, Real FX, Chanock SJ, Perez-Jurado LA: Mosaic Uniparental Disomies and Aneuploidies as Large Structural Variants of the Human Genome. Am J Hum Genet 2010, 87:129-138.

14. Iourov IY, Vorsanova SG, Liehr T, Yurov YB: Aneuploidy in the normal, Alzheimer's disease and ataxia-telangiectasia brain: Differential expression and pathological meaning. Neurobiol Dis 2009, 34:212-220.

15. Ledbetter DH, Zachary JM, Simpson JL, Golbus MS, Pergament E, Jackson L, Mahoney MJ, Desnick RJ, Schulman J, Copeland KL, Verlinsky Y, Yangfeng T, Schonberg SA, Babu A, Tharapel A, Dorfmann A, Lubs HA, Rhoads GG, Fowler SE, Delacruz F: Cytogenetic Results from the United-States Collaborative Study on Cvs. Prenat Diagn 1992, 12:317-345.

16. Hsu LYF, Yu MT, Richkind KE, Vandyke DL, Crandall BF, Saxe DF, Khodr GS, Mennuti M, Stetten G, Miller WA, Priest JH: Incidence and significance of chromosome mosaicism involving an autosomal structural abnormality diagnosed prenatally through amniocentesis: A collaborative study. Prenat Diagn 1996, 16:1-28.

17. Hoang S, Ahn J, Mann K, Bint S, Mansour S, Homfray T, Mohammed S, Ogilvie CM: Detection of mosaicism for genome imbalance in a cohort of 3,042 clinical cases using an oligonucleotide array CGH platform. Eur $J$ Med Genet 2010, 54:121-129.

18. Blouin JL, Aurias A, Creaugoldberg N, Apiou F, Alcaideloridan C, Bruel A, Prieur M, Kraus J, Delabar JM, Sinet PM: Cytogenetic and Molecular Analysis of A Denovo Tandem Duplication of Chromosome-21. Hum Genet 1991, 88:167-174

19. De Silva D, Massie D, Drummond J, Couzin D, Dean JCS: Mosaicism for a tandem duplication dup(1)(q12q22) in an 18 year old female. J Med Genet 1998, 35:600-603. 
20. Dixon JW, Costa T, Teshima IE: Mosaicism for Duplication 12Q (12Q13-] Q24.2) in A Dysmorphic Male Infant. J Med Genet 1993, 30:70-72.

21. Erez A, Li J, Geraghty MT, Ben-Shachar S, Cooper ML, Mensing DE, Vonalt KD, Ou Z, Pursley AN, Chinault AC, Patel A, Cheung SW, Sahoo T: Mosaic Deletion 11p13 in a Child With Dopamine Beta-Hydroxylase Deficiency-Case Report and Review of the Literature. Am J Med Genet A 2010, 152A:732-736

22. Faivre L, Viot G, Prieur M, Turleau C, Gosset P, Romana S, Munnich A, Vekemans M, Cormier-Daire V: Apparent Sotos syndrome (cerebral gigantism) in a child with trisomy 20p11.2-p12.1 mosaicism. Am J Med Genet 2000, 91:273-276.

23. Gardner RJM, Dockery HE, Fitzgerald PH, Parfitt RG, Romain DR, Scobie N, Shaw RL, Tumewu P, Watt AJ: Mosaicism with A Normal-Cell Line and An Autosomal Structural Rearrangement. J Med Genet 1994, 31:108-114.

24. Karaoguz MY, Biri A, Pala E, Kan D, Poyraz A, Kurdoglu M, Percin EF: A case with mosaic partial duplication of 1q: Prenatal and postmortem clinical and cytogenetic evaluations. Genet Couns 2006, 17:197-204.

25. Kotzot D, Schinzel A: Paternal meiotic origin of $\operatorname{der}(21 ; 21)(q 10 ; q 10)$ mosaicism $[46, X X / 46, X X, \operatorname{der}(21 ; 21)(q 10 ; q 10),+21]$ in a girl with mild Down syndrome. Eur J Hum Genet 2000, 8:709-712.

26. Kotzot D, Martinez MJ, Bagci G, Basaran S, Baumer A, Binkert F, Brecevic L, Castellan C, Chrzanowska K, Dutly F, Gutkowska A, Karauzum SB, KrajewskaWalasek M, Luleci G, Miny P, Riegel M, Schuffenhauer S, Seidel H, Schinzel A: Parental origin and mechanisms of formation of cytogenetically recognisable de novo direct and inverted duplications. J Med Genet 2000, 37:281-286.

27. Martinez A, Ramos S, Gonzalez-Del AA, Alcantara MA, Molina B, Carnevale A: Duplication $2 p$ and monosomy $8 p$ in mosaicism: clinical, molecular cytogenetic and molecular markers of a unique case. Rev Invest Clin 2007, 59:444-448.

28. Patel C, Hardy G, Cox P, Bowdin S, McKeown C, Russell AB: Mosaic Trisomy 1q: The Longest Surviving Case. Am J Med Genet A 2009, 149A:1795-1800.

29. Rauen KA, Bitts SM, Li L, Golabi M, Cotter PD: Tandem duplication mosaicism: characterization of a mosaic dup(5q) and review. Clin Genet 2001, 60:366-370.

30. Sarri C, Gyftodimou J, Avramopoulos D, Grigoriadou M, Pedersen W, Pandelia E, Pangalos C, Abazis D, Kitsos G, Vassilopoulos D, BrondumNielsen K, Petersen MB: Partial trisomy 17q22-qter and partial monosomy Xq27-qter in a girl with a de novo unbalanced translocation due to a postzygotic error: Case report and review of the literature on partial trisomy 17qter. Am J Med Genet 1997, 70:87-94

31. Scheuerle A, Heller K, Elder F: Complete trisomy 1q with mosaic $Y ; 1$ translocation: A recurrent aneuploidy presenting diagnostic dilemmas. Am J Med Genet A 2005, 138A:166-170.

32. Schinzel A, Kotzot D, Brecevic L, Robinson WP, Dutly F, Dauwerse $H$ Binkert F, Baumer A, Ausserer B: Trisomy first, translocation second, uniparental disomy and partial trisomy third: A new mechanism for complex chromosomal aneuploidy. Eur J Hum Genet 1997, 5:308-314.

33. Stallings $R$, Vaughan D, Hall K, Joyce C, Ryan F, Barton D, Geraghty M: Mosaicism for trisomy $3 q$ arising from an unbalanced, de novo $t(3 ; 15)$. J Med Genet 1997, 34:512-514.

34. Zaslav AL, Fallet S, Blumenthal D, Jacob J, Fox J: Mosaicism with a normal cell line and an unbalanced structural rearrangement. Am J Med Genet 1999, 82:15-19.

35. Zeng S, Patil SR, Yankowitz J: Prenatal detection of mosaic trisomy $1 \mathrm{q}$ due to an unbalanced translocation in one fetus of a twin pregnancy following in vitro fertilization: a postzygotic error. Am J Med Genet A 2003, 120A:464-469.

36. Tharapel AT, Michaelis RC, Velagaleti GVN, Laundon CH, Martens PR, Buchanan PD, Teague KE, Tharapel SA, Wilroy RS: Chromosome duplications and deletions and their mechanisms of origin. Cytogenet Cell Genet 1999, 85:285-290.

37. Ramsay M, Pfaffenzeller W, Kotze E, Bhengu L, Essop F, de Ravel T: Chimerism in Black Southern African Patients with True Hermaphroditism 46, XX/47XY,+21 and 46, XX/46, XY. Ann N Y Acad Sci 2009, 1151:68-76.

38. Font-Montgomery E, Stone KM, Weaver DD, Vance GH, Das S, Thurston VC: Clinical outcome and follow-up of the first reported case of RussellSilver syndrome with the unique combination of maternal uniparental heterodisomy 7 and mosaic trisomy 7. Birth Defects Res A Clin Mol Teratol 2005, 73:577-582.
39. Kagami M, Kato F, Matsubara K, Sato T, Nishimura G, Ogata T: Relative frequency of underlying genetic causes for the development of UPD(14) pat-like phenotype. Eur J Hum Genet 2012.

40. Mergenthaler S, Wollmann HA, Burger B, Eggermann K, Kaiser P, Ranke MB, Schwanitz G, Eggermann T: Formation of uniparental disomy 7 delineated from new cases and a UPD7 case after trisomy 7 rescue. Presentation of own results and review of the literature. Ann Genet 2000, 43:15-21.

41. Vermeesch JR, Melotte C, Froyen G, Van Vooren S, Dutta B, Maas N, Vermeulen S, Menten B, Speleman F, De Moor B, Van Hummelen P, Marynen P, Fryns JP, Devriendt K: Molecular karyotyping: Array CGH quality criteria for constitutional genetic diagnosis. I Histochem Cytochem 2005, 53:413-422.

42. Nannya Y, Sanada M, Nakazaki K, Hosoya N, Wang LL, Hangaishi A, Kurokawa M, Chiba S, Bailey DK, Kennedy GC, Ogawa S: A robust algorithm for copy number detection using high-density oligonucleotide single nucleotide polymorphism genotyping arrays. Cancer Res 2005, 65:6071-6079.

43. Vermeesch JR, Mertens G, David G, Marynen P: Assignment of the Human Glypican Gene (Gpc1) to 2Q35-Q37 by Fluorescence In-Situ Hybridization. BMC Genomics 1995, 25:327-329.

44. Korn JM, Kuruvilla FG, McCarroll SA, Wysoker A, Nemesh J, Cawley S, Hubbell E, Veitch J, Collins PJ, Darvishi K, Lee C, Nizzari MM, Gabriel SB, Purcell S, Daly MJ, Altshuler D: Integrated genotype calling and association analysis of SNPs, common copy number polymorphisms and rare CNVs. Nat Genet 2008, 40:1253-1260.

45. The R Project for Statistical Computing. [http://www.r-project.org/]

46. Rabbee N, Speed TP: A genotype calling algorithm for affymetrix SNP arrays. Bioinformatics 2006, 22:7-12

47. Wang K, Li MY, Hadley D, Liu R, Glessner J, Grant SFA, Hakonarson H, Bucan M: PennCNV: An integrated hidden Markov model designed for high-resolution copy number variation detection in whole-genome SNP genotyping data. Genome Res 2007, 17:1665-1674.

48. Sun W, Wright FA, Tang ZZ, Nordgard SH, Van Loo P, Yu TW, Kristensen VN, Perou CM: Integrated study of copy number states and genotype calls using high-density SNP arrays. Nucleic Acids Res 2009, 37:5365-5377.

49. Ensembl. [http://www.ensembl.org].

50. UCSC Genome Bioinformatics. [http://genome.ucsc.edu/].

doi:10.1186/1755-8166-5-19

Cite this article as: Robberecht et al: Meiotic errors followed by two parallel postzygotic trisomy rescue events are a frequent cause of constitutional segmental mosaicism. Molecular Cytogenetics 2012 5:19.

\section{Submit your next manuscript to BioMed Central and take full advantage of:}

- Convenient online submission

- Thorough peer review

- No space constraints or color figure charges

- Immediate publication on acceptance

- Inclusion in PubMed, CAS, Scopus and Google Scholar

- Research which is freely available for redistribution

Submit your manuscript at www.biomedcentral.com/submit
C Biomed Central 